\title{
Predicción seamless nowcasting en Europa y AEMET
}

https://doi.org/10.31978/639-19-010-0.021

\author{
Alfons Callado Pallarés ${ }^{1}$ (acalladop@aemet.es) \\ José Antonio García-Moya Zapata² (jgarciamoyaz@aemet.es) \\ Mauri Martínez Sánchez ${ }^{1}$ (mmartinezs@aemet.es)
}

${ }^{1}$ AEMET / Delegación Territorial en Cataluña / Grupo de Predecibilidad

${ }^{2}$ AEMET / Departamento de Desarrollo y Aplicaciones / Área de Innovación / Grupo de Predecibilidad (jubilado)

\section{RESUMEN}

Diversos Servicios Meteorológicos Nacionales en Europa están apostando por la predicción seamless o sin costuras de nowcasting o predicción a muy corto plazo de muy alta resolución espaciotemporal con productos dirigidos tanto internamente a sus predictores operativos como a usuarios externos. Las predicciones seamless-nowcasting se basan en dar predicciones continuas de 0 a 12 horas extrapolando las observaciones en las primeras horas (ej., de 0 a 4 horas) y enlazando (ej., enlace entre las 2 y las 4 horas) luego con las predicciones de modelos numéricos de predicción y con ensembles o predicciones por conjuntos (ej., de 2 a 12 horas).

Usualmente se aplican las técnicas seamless-nowcasting a predicciones de la precipitación, nubosidad, a la intensidad y dirección del viento, probabilidad de rayos, etcétera. Un ejemplo podría ser pseudoimágenes de reflectividades radar de 0 a 6 horas.

Se muestran en la presentación algunos de los resultados y ejemplos presentados en diversas ponencias del Workshop «Connecting Nowcasting and mesoscale EPS», conjunto de los proyectos ASIST y SRNWP-EPS Phase-II de EUMETNET celebrado en Bolonia entre los días 16 y 18 de mayo de 2018.

En AEMET, con el proyecto «nowcRadiation» con Red Eléctrica de España, hay una primera experiencia de seamless-nowcasting para la radiación solar. Detalles de la experiencia serán presentados a cargo de Mauri Martínez en la presentación «nowcRadiation Software de nowcasting para predicción de la radiación solar» del presente simposio.

Y actualmente desde el Grupo de Predecibilidad de AEMET, que ha desarrollado el ensemble AEMET- $\gamma$ SREPS, se participa en la propuesta de la acción eCOST SHINE: «Seamless High Impact weather Nowcasting with Ensembles» de la Unión Europea para la cooperación científica y técnica.

Para terminar nos preguntamos si AEMET, como otros Servicios Meteorológicos Europeos, debería también apostar por la predicción seamless-nowcasting enfocada sobre todo a los procesos convectivos que pueden tener un gran impacto socioeconómico en España.

PALABRAS CLAVE: seamless; nowcasting; predicción sin costuras; predicción inmediata; predicción por conjuntos. 
